\title{
Soft tissue sarcomas of the distal lower extremities: A single-institutional analysis of the prognostic significance of surgical margins in 120 patients
}

\author{
KAMRAN HARATI, PASCAL KIRCHHOFF, BJÖRN BEHR, ADRIEN DAIGELER, \\ OLE GOERTZ, TOBIAS HIRSCH, MARCUS LEHNHARDT and ANDREJ RING \\ Department of Plastic Surgery, Burn Center, Hand Center, Sarcoma Reference Center, \\ BG-University Hospital Bergmannsheil, D-44789 Bochum, Germany
}

Received February 14, 2016; Accepted May 23, 2016

DOI: $10.3892 /$ or.2016.4862

\begin{abstract}
Soft tissue sarcomas (STS) arising in the distal lower extremities pose a therapeutic challenge due to concerns of functional morbidity. The impact of surgical margins on local recurrence-free survival (LRFS) and overall survival (OS) still remains controversial. The aim of this study was to identify prognostic indicators of survival and functional outcome in patients with STS of the distal lower extremities through a long-term follow-up. Between 1999 and 2014, 120 patients with STS of the foot, ankle and lower leg were treated surgically at our institution. The median follow-up was 6.3 years. The results reveal that the 5-year estimate of the OS rate was 80.0\% [95\% confidence interval (CI): 69.6-87.1] for the entire series. Surgical margins attained at the resection of the primary tumor did not influence OS significantly [5-year OS: R0 80.5\% (69.7-87.9) vs. R1 74.1\% (28.9-93.0); P=0.318]. Within the R0 subgroup, negative surgical margin widths $\leq 1$ and $>1 \mathrm{~mm}$ led to similar outcomes, as well as $\leq 5$ and $>5 \mathrm{~mm}$, respectively. In the multivariate analysis, significant adverse prognostic features included male gender and age $>60$ years at the time point of primary diagnosis. In conclusion, the data from this study could not underscore the long-term benefit of negative margins achieved at the resection of the primary tumor. Surgical efforts should aim at function-sparing resections when feasible with negative margins. Here, close negative margins seem to be adequate.
\end{abstract}

Correspondence to: Dr Kamran Harati, Department of Plastic Surgery, Burn Center, Hand Center, Sarcoma Reference Center, BG-University Hospital Bergmannsheil, Buerkle-de-la-Camp-Platz 1, D-44789 Bochum, Germany

E-mail: kamran.harati@t-online.de

Key words: sarcoma, foot, ankle, extremity, survival, margin

\section{Introduction}

Soft tissue sarcomas (STS) are a heterogeneous group of rare malignant tumors that account for $\sim 1 \%$ of all adult malignancies and occur in $\sim 60 \%$ of all cases in the extremities $(1,2)$. According to the content of soft tissues, the lower extremities are affected more frequently than the upper extremities, with a ratio of $\sim 4: 1(3,4)$.

In patients with primary STS of the extremities, the therapy of choice involves limb-sparing surgical resection with negative margins, usually followed by radiation treatment to decrease local recurrence (4-6). There have been several analyses of the prognostic factors influencing overall survival (OS) in patients with extremity STS (7-11). Among these factors, histologic grade, depth, anatomic site, tumor size and histologic subtype are considered the most significant for OS. The achievement of negative surgical margins in primary STS has been determined to be an important factor for improving local recurrence-free survival (LRFS). However, the implementation of radical surgery in the distal region of the lower extremity is often difficult due to the limited soft and bony tissue situation. Here, attainment of negative surgical margins may require extensive surgery and could result in considerable impairment of extremity function, particularly in cases of large tumor size or localization adjacent to critical anatomic structures. It is therefore important to determine whether an aggressive surgical approach with the goal of negative margins can be justified for STS at the distal lower extremities.

In patients with extremity STS in general, the impact of microscopic surgical margins on OS is still a subject of debate. Large single-institutional studies investigating the clinical significance of surgical margins have presented inconsistent results (4,12-18). Accordingly, smaller but more specific studies pertaining the surgical treatment of STS in the distal lower extremities were not able to establish an association between microscopic margins and OS (19-23). Moreover, the follow-up data in these studies were reported only inconsistently whereas longer follow-up periods seem reasonable, especially for slow-growing STS subtypes. Therefore, the question remains whether aggressive local disease control would have a posi- 
tive long-term impact on OS in patients with STS at the distal lower extremities.

The aim of this study was to identify prognostic indicators of survival and functional outcome in patients with STS at the lower extremities by reviewing our institutional experience. In particular, we focused on the effect of surgical margins on disease outcome.

\section{Patients and methods}

Patients. Between September 1999 and May 2014, 157 patients with STS of the distal lower extremities were treated surgically at our institution. STS extending distally to the level of the knee joints were included, but tumors involving the level of the knee joints or located proximally were excluded. A total of 104 of the 157 patients presented with primary disease in our institution. Forty-three patients were subsequently referred to our center after incomplete resection or the diagnosis of recurrence at least 3 months after definitive surgery on the primary tumor which had been performed at other institutions. From this group, we excluded 28 patients because essential data regarding the initial surgical procedure, such as tumor size or margin status were not available. Furthermore, 9 patients, including those from foreign countries, were lost to follow-up. Thus, we restricted analyses to 120 participants with full information available on the outcome and surgical margins at the initial procedure. They were assessed and their clinicopathological characteristics are summarized in Tables I and II. Patient follow-up was obtained from our database, medical records and patient correspondence. The study was approved by the local Ethics Committee.

Treatment. The goal of surgical treatment for all patients was function-preserving and limb-sparing resection of the primary tumor with clear margins, according to the preoperative imaging results in curative intent. Plastic reconstructive surgery involving split thickness skin grafts, local or free flaps were used for the coverage of resulting soft tissue defects. Based on prognostic factors predicting an increased risk of disease progression, several patients received adjuvant radiation and/or chemotherapy using generally anthracycline-based regimens. The indication for adjuvant radiation or chemotherapy was given at the discretion of the interdisciplinary tumor board of either our institution or the referring institutions.

Sixty patients received adjuvant radiotherapy after resection of their primary tumor with a median overall dose of 58.9 Gray (range, 36.0-70.0). Further four patients underwent first adjuvant radiotherapy after initial or second local recurrence. Twelve patients received adjuvant chemotherapy after resection of the primary tumor. Eleven of them were treated with doxorubicin or epirubicin combined with ifosfamide. One patient received cyclophosphamide and vinblastine.

Histopathological classification. All tumors were diagnosed and classified using the guidelines of the French Federation of Cancer Centres (FNCLCC) and the latest World Health Organisation (WHO). All pathology slides were analyzed or reviewed for consensus diagnosis by experienced soft tissue pathologists. In specialized cases, an expert second opinion was obtained in Germany (Professor Katenkamp, Jena).
Statistical analysis. All patients were retrospectively analyzed regarding possible prognostic factors influencing survival (Tables I and II). OS was defined as the time period from the date of surgery for primary disease to the date of death from any cause. Survival rates were estimated according to the Kaplan-Meier method with respective 95\% confidence intervals (CIs) and were compared using the log-rank test. Multivariate analyses were performed using the Cox proportional hazards model. Variables that were associated with $\mathrm{P}<0.1$ in the univariate analysis were included in the multivariate regression to assess independent prognostic factors for OS. $\mathrm{P}<0.05$ was considered statistically significant. Mann-Whitney U test and Kruskal-Wallis test were used to detect any correlations between functional outcome and different tumor and treatment characteristics, respectively. The functional outcome could be assessed through the Toronto extremity Salvage Score questionnaire (TESS), Foot Function Index (FFI) and 36-Item Short Form Health Survey (SF-36) at the cut-off date. The data analysis was performed using the statistical program Stata (version 11.2; StataCorp, College Station, TX, USA).

\section{Results}

Patient characteristics and surgical margins. The mean age at the time of primary diagnosis was 57.4 years (range, 16.5-89.2). There were 60 female and 60 male individuals. Tumors were located in the lower legs in 87 patients (72.5\%); at the ankle region in 14 patients $(11.7 \%)$; and in the foot in 19 patients $(15.8 \%)$. The distribution of the histologic grading was G1 in 16 cases (13.3\%), G2 in $52(43.3 \%)$ and G3 in $52(43.3 \%)$. In total, 37 patients had at least one local recurrence, whereas 18 patients had two or more local recurrences (range, 2-10). Over time, 31 patients developed distant metastases. From these patients 20 had pulmonary metastases. The Kaplan-Meier estimated rate of 5-year distant metastasis-free survival after primary diagnosis was $76.5 \%$ (95\% CI: 66.5-83.9) for the entire cohort.

In order to determine the impact of surgical resection margins on survival, we analyzed the two following variables. In 'margin status after primary resection', we assessed OS depending on the resection status that was achieved at the resection of the primary tumor in our or the referring institution. The primary resection led to microscopically negative margins (R0) in 108 patients $(90.0 \%)$, whereas 12 patients $(10.0 \%)$ were left with microscopically positive margins (R1) and no patient with macroscopically positive margins (R2).

In those patients with negative margins after primary resection, we additionally assessed the impact of the clear surgical margin width in 'distance of closest negative surgical margin at resection of the primary tumor' which was available in 71 of 108 patients within the R0 subgroup.

Follow-up. As of November 2015 (cut-off date), the reverse Kaplan-Meier estimate of median follow-up after primary diagnosis was 6.3 years (95\% CI: 5.3-9.2) (24). At the cut-off date, 80 patients had no evidence of disease whereas 11 patients were alive with metastatic disease and 4 patients with residual localized disease. During follow-up, 18 patients died from disease and 7 patients from other causes. 
Table I. Results of univariate analyses to determine factors predictive of overall survival in 120 patients with soft tissue sarcomas of the distal lower extremities.

\begin{tabular}{|c|c|c|c|c|c|}
\hline & $\mathrm{N}$ & $\begin{array}{l}\text { Estimated 1-year } \\
\text { OS }(95 \% \text { CI })\end{array}$ & $\begin{array}{l}\text { Estimated 2-year } \\
\text { OS }(95 \% \mathrm{CI})\end{array}$ & $\begin{array}{l}\text { Estimated 5-year } \\
\text { OS }(95 \% \text { CI })\end{array}$ & $\begin{array}{c}\text { P-value } \\
(\text { log-rank })^{\mathrm{a}}\end{array}$ \\
\hline \multicolumn{6}{|l|}{ Age (years) } \\
\hline$<60$ & 57 & $100(-)$ & $100(-)$ & $94.0(78.2-98.5)$ & 0.036 \\
\hline$\geq 60$ & 63 & $96.5(86.6-99.1)$ & $88.6(76.4-94.7)$ & $68.5(53.1-79.8)$ & \\
\hline \multicolumn{6}{|l|}{ Sex } \\
\hline Female & 60 & $100(-)$ & $95.3(82.7-98.8)$ & $90.0(75.3-96.1)$ & 0.004 \\
\hline Male & 60 & $96.5(86.6-99.1)$ & $92.6(81.5-97.2)$ & $71.1(55.1-82.2)$ & \\
\hline \multicolumn{6}{|l|}{ Tumor size $(\mathrm{cm})$} \\
\hline$<5$ & 62 & $98.2(88.2-99.8)$ & $96.3(86.0-99.1)$ & $84.8(70.5-92.5)$ & 0.068 \\
\hline$\geq 5$ & 58 & 98.0 (86.6-99.7) & $91.1(77.9-96.6)$ & $73.9(56.6-85.2)$ & \\
\hline \multicolumn{6}{|l|}{ Tumor depth } \\
\hline Epifascial & 60 & $100(-)$ & $96.0(85.1-99.0)$ & 83.5 (68.3-91.9) & 0.308 \\
\hline Subfascial & 60 & $96.3(85.9-99.1)$ & $91.7(79.3-96.8)$ & $75.8(59.3-86.3)$ & \\
\hline \multicolumn{6}{|l|}{ Tumor site } \\
\hline Foot/ankle & 32 & $100(-)$ & $96.6(77.9-99.5)$ & $77.8(54.3-90.2)$ & 0.479 \\
\hline Lower leg & 88 & $97.4(90.1-99.4)$ & $93.0(84.0-97.0)$ & $80.8(68.5-88.7)$ & \\
\hline \multicolumn{6}{|l|}{ Grading } \\
\hline G1 & 16 & $100(-)$ & $93.3(61.3-99.0)$ & $86.2(55.0-96.4)$ & 0.123 \\
\hline $\mathrm{G} 2$ & 52 & $100(-)$ & $97.4(83.2-99.6)$ & $88.0(70.9-95.3)$ & \\
\hline G3 & 52 & 95.7 (83.7-98.9) & $90.7(76.9-96.4)$ & $71.1(53.7-82.9)$ & \\
\hline \multicolumn{6}{|l|}{ Histologic subset } \\
\hline Liposarcoma & 21 & $100(-)$ & $100(-)$ & $79.6(48.9-93.0)$ & 0.315 \\
\hline Non-liposarcoma & 99 & $97.7(91.2-99.4)$ & $92.5(84.1-96.6)$ & $80.1(68.5-87.8)$ & \\
\hline NOS & 40 & $94.1(78.5-98.5)$ & $90.9(74.3-97.0)$ & $72.1(51.5-85.1)$ & 0.229 \\
\hline Non-NOS & 80 & $100(-)$ & $95.4(86.5-98.5)$ & $83.8(71.0-91.3)$ & \\
\hline Synovial sarcoma & 18 & $100(-)$ & $92.9(59.1-99.0)$ & $82.5(45.1-95.5)$ & 0.460 \\
\hline Non-synovial sarcoma & 102 & $97.8(91.6-99.5)$ & $94.2(86.5-97.5)$ & $79.6(68.2-87.2)$ & \\
\hline Leiomyosarcoma & 14 & $100(-)$ & $91.7(53.9-98.8)$ & 91.7 (53.9-98.8) & 0.832 \\
\hline Non-leiomyosarcoma & 106 & $97.9(91.8-99.5)$ & $94.3(86.7-97.6)$ & $78.7(67.5-86.5)$ & \\
\hline
\end{tabular}

${ }^{a}$ Log-rank test for equality of survivor functions. OS, overall survival; CI, confidence interval.

Recurrence-free time from primary diagnosis to initial recurrence. The local recurrence-free survival (LRFS) was calculated from the date of primary surgery to initial local recurrence. The 5-year rate of LRFS was $65.0 \%$ (95\% CI: 54.0-71.1) for the entire cohort. Histologic subtypes had no significant influence on LRFS. Notably, patients with adjuvant radiation tended to have a prolonged LRFS compared with patients whose primary tumors were not treated with radiation [5-year LRFS: $71.6 \%$ (56.5-82.2) vs. 57.6\% (40.5-71.3)], but the difference was not statistically significant in the univariate analysis $(\mathrm{P}=0.159)$. Microscopic margin status attained at the first oncological resection had no statistical significant impact on LRFS [5-year LRFS: R0 88.9\% (43.3-98.4) vs. R1 $63.1 \%$ (51.5-72.6); $\mathrm{P}=0.521]$.

Survival. In the entire series, the 5-year estimate of the OS rate was $80.0 \%$ (95\% CI: 69.6-87.1), whereas the estimated 5-year rate of OS was $66.3 \%$ (95\% CI: 44.8-81.0) for patients with local recurrence. Patients who developed distant metastases had a 5-year survival of $18.8 \%$ (95\% CI: 5.0-39.5). The median survival time after diagnosis of initial metastasis was 2.8 years (95\% CI: 1.2-4.7).

Univariate analysis of survival. Age and gender were found to have a prognostic significance on OS (Table I, Fig. 1A and B). Patients older than 60 years had a significantly diminished outcome when compared with younger patients at the time point of primary diagnosis [5-year OS: $94.0 \%$ (78.2-98.5) vs. 68.5\% (53.1-79.8); $\mathrm{P}=0.036]$. In the entire series, women had more favourable prognoses than men. The 5-year OS rates were estimated to be $90.0 \%$ (95\% CI: 75.3-96.1) for women and 71.1\% (95\% CI: 55.1-82.2) for men $(\mathrm{P}=0.004)$.

Patients with primary tumors $<5 \mathrm{~cm}$ tended to have an improved OS [5-year OS: $84.8 \%$ (95\% CI: 70.5-92.5)] when compared with patients with larger tumors [5-year 
Table II. Univariate analyses on overall survival depending on treatment characteristics.

\begin{tabular}{|c|c|c|c|c|c|}
\hline & $\mathrm{N}$ & $\begin{array}{l}\text { Estimated 1-year } \\
\text { OS }(95 \% \mathrm{CI})\end{array}$ & $\begin{array}{l}\text { Estimated 2-year } \\
\text { OS }(95 \% \mathrm{CI})\end{array}$ & $\begin{array}{l}\text { Estimated 5-year } \\
\text { OS }(95 \% \text { CI })\end{array}$ & $\begin{array}{l}\text { P-value } \\
(\log -\text { rank })^{\mathrm{a}}\end{array}$ \\
\hline \multicolumn{6}{|l|}{$\begin{array}{l}\text { Margin status after primary } \\
\text { resection }\end{array}$} \\
\hline R0 & 108 & $98.0(92.1-99.5)$ & 94.5 (87.2-97.7) & 80.5 (69.7-87.9) & 0.318 \\
\hline $\mathrm{R} 1$ & 12 & $100(-)$ & $88.9(43.3-98.4)$ & $74.1(28.9-93.0)$ & \\
\hline \multicolumn{6}{|l|}{$\begin{array}{l}\text { Distance of closest negative surgical } \\
\text { margin at resection of the primary } \\
\text { tumor (R0 group) (mm) }\end{array}$} \\
\hline$\leq 1$ & 20 & $94.4(66.6-99.2)$ & 88.5 (61.4-97.0) & $50.3(19.6-74.8)$ & 0.068 \\
\hline$>1$ & 51 & $97.8(85.3-99.7)$ & $92.6(78.8-97.6)$ & $83.4(66.4-92.3)$ & \\
\hline$\leq 5$ & 52 & $95.6(83.7-98.9)$ & $90.4(76.2-96.3)$ & $69.4(49.9-82.5)$ & 0.981 \\
\hline$>5$ & 19 & $100(-)$ & $93.8(63.2-99.1)$ & $87.1(57.3-96.6)$ & \\
\hline \multicolumn{6}{|l|}{$\begin{array}{l}\text { Wound closure after primary } \\
\text { resection }\end{array}$} \\
\hline Primary closure & 36 & $96.8(79.2-99.5)$ & $96.8(79.2-99.5)$ & $92.2(71.5-98.0)$ & 0.887 \\
\hline $\begin{array}{l}\text { Non-primary closure } \\
\text { (plastic surgical soft tissue coverage) }\end{array}$ & 55 & 97.9 (86.1-99.7) & 90.7 (77.1-96.4) & 87.5 (72.2-94.7) & \\
\hline \multicolumn{6}{|l|}{ Amputation } \\
\hline Yes & 29 & $100(-)$ & $96.4(77.2-99.5)$ & $59.4(37.5-75.8)$ & 0.001 \\
\hline No & 91 & $97.5(90.3-99.4)$ & $93.0(83.9-97.0)$ & $89.2(78.5-94.8)$ & \\
\hline \multicolumn{6}{|l|}{$\begin{array}{l}\text { Adjuvant radiotherapy after } \\
\text { primary resection }\end{array}$} \\
\hline Yes & 60 & $98.2(87.8-99.7)$ & $96.1(85.2-99.0)$ & $80.1(65.2-89.2)$ & 0.564 \\
\hline No & 60 & $98.1(87.1-99.7)$ & 91.7 (79.4-96.8) & $80.2(63.8-89.7)$ & \\
\hline \multicolumn{6}{|l|}{$\begin{array}{l}\text { Adjuvant chemotherapy after } \\
\text { primary resection }\end{array}$} \\
\hline Yes & 12 & $91.7(53.9-98.8)$ & $91.7(53.9-98.8)$ & $73.3(24.3-93.4)$ & 0.947 \\
\hline No & 108 & $99.0(93.0-99.9)$ & 94.4 (87.1-97.6) & $80.7(69.9-88.0)$ & \\
\hline
\end{tabular}

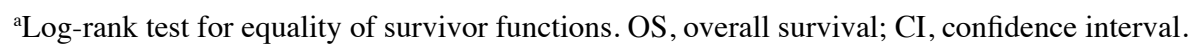

OS: $73.9 \%$ (95\% CI: 56.6-85.2)], although this survival distribution failed to reach statistical significance in the univariate analysis, and a borderline P-value was attained $(\mathrm{P}=0.068)$ (Fig. 2A). Notably, histologic grade as well as tumor site and depth did not influence OS (Fig. 2B and C). Regarding the different histologic subsets, all patients had comparable OS rates (Table II).

In the univariate analysis, the surgical margin status attained at the resection of the primary tumor failed to reach a prognostic significance. Remarkably, patients who underwent only an incomplete resection with microscopically positive margins (R1) had an outcome similar to patients who underwent a R0 resection of their primary tumor [5-year OS: 74.1\% (28.9-93.0) vs. 80.5\% (69.7-87.9); $\mathrm{P}=0.318$ ] (Fig. 3A). Within the R0 group, the negative surgical margin width, even under $1 \mathrm{~mm}$ in the closest distance to the tumor tissue, did not influence the OS rates. Surgical margin widths $\leq 1$ and $>1 \mathrm{~mm}$ led to similar outcomes, as well as $\leq 5$ and $>5 \mathrm{~mm}$, respectively (Table II, Fig. 3B). However, patients who had to undergo an amputation during the course of disease had a significantly worse outcome when compared with patients who were not amputated [5-year OS: 59.4\% (37.5-75.8) vs. 89.2\% (78.5-94.8); $\mathrm{P}=0.001$ ] (Fig. 3C). Within the cohort of patients who did not undergo amputation, primary wound closure and plastic surgical soft tissue coverage with split thickness skin grafting, local or free flaps led to a similar outcomes [5-year OS: $92.2 \%$ (71.5-98.0) vs. 87.5\% (72.2-94.7); $\mathrm{P}=0.887]$. Similar to findings for LRFS, adjuvant radiation after initial oncologic resection did not alter OS [5-year OS: $80.1 \%(65.2-89.2)$ vs. $80.2 \%$ (63.8-89.7); $\mathrm{P}=0.564]$.

Multivariate analysis of survival. In the Cox model, significant prognostic factors for OS were only gender and age (Table III). The hazard ratio (HR) for death was 4.7 (95\% CI: 1.01-21.84; 
A

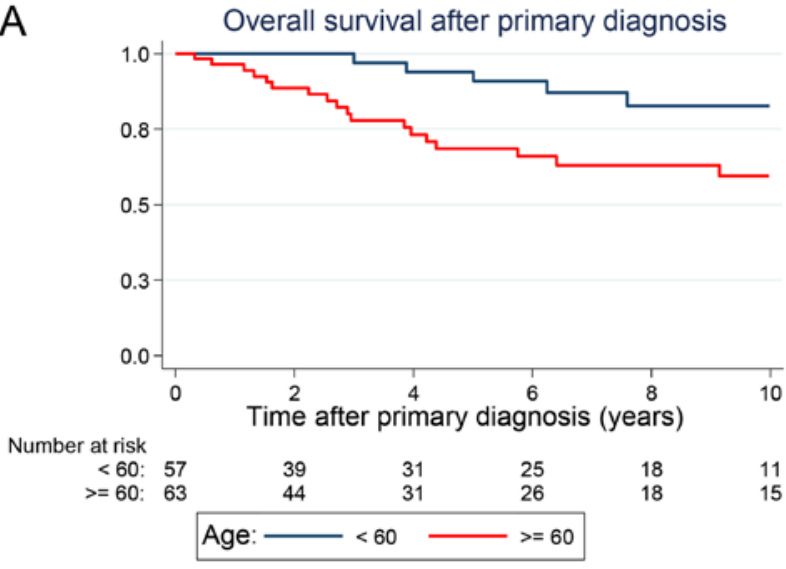

B

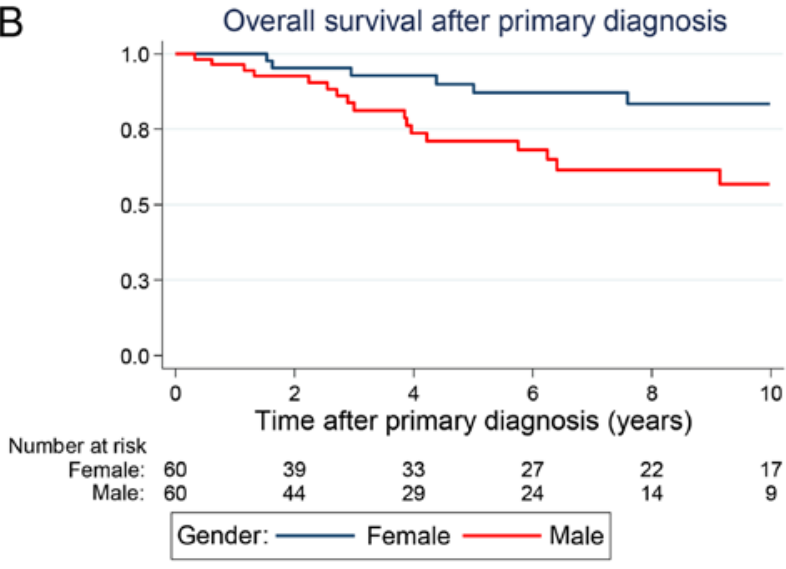

Figure 1. Estimated overall survival curves after primary diagnosis according to (A) age and (B) gender.

Table III. Results of multivariate analysis on overall survival according to Cox proportional hazards model.

\begin{tabular}{lccc}
\hline & $\begin{array}{c}\text { Hazard } \\
\text { ratio }\end{array}$ & $95 \%$ CI & P-value \\
\hline $\begin{array}{l}\text { Gender } \\
\text { Male (vs. female) }\end{array}$ & 4.70 & $1.01-21.84$ & 0.048 \\
$\begin{array}{l}\text { Age } \\
\geq 60 \text { years (vs. }<60 \text { years) }\end{array}$ & 3.77 & $1.35-10.52$ & 0.011 \\
$\begin{array}{l}\text { Tumor size } \\
\geq 5 \text { cm (vs. <5 cm) }\end{array}$ & 0.94 & $0.27-3.23$ & 0.916 \\
$\begin{array}{l}\text { Distance of closest } \\
\text { negative surgical margin at } \\
\text { primary resection (R0 group) } \\
>0.1 \mathrm{~cm} \text { (vs. } \leq 0.1 \mathrm{~cm})\end{array}$ & 0.42 & $0.11-1.61$ & 0.208 \\
$\begin{array}{l}\text { Amputation } \\
\text { Yes (vs. no) }\end{array}$ & & & \\
\hline
\end{tabular}

CI, confidence interval.

$\mathrm{P}=0.048$ ) for male patients and 3.77 (95\% CI: 1.35-10.52; $\mathrm{P}=0.011)$ for patients older than 60 years. Amputation was a
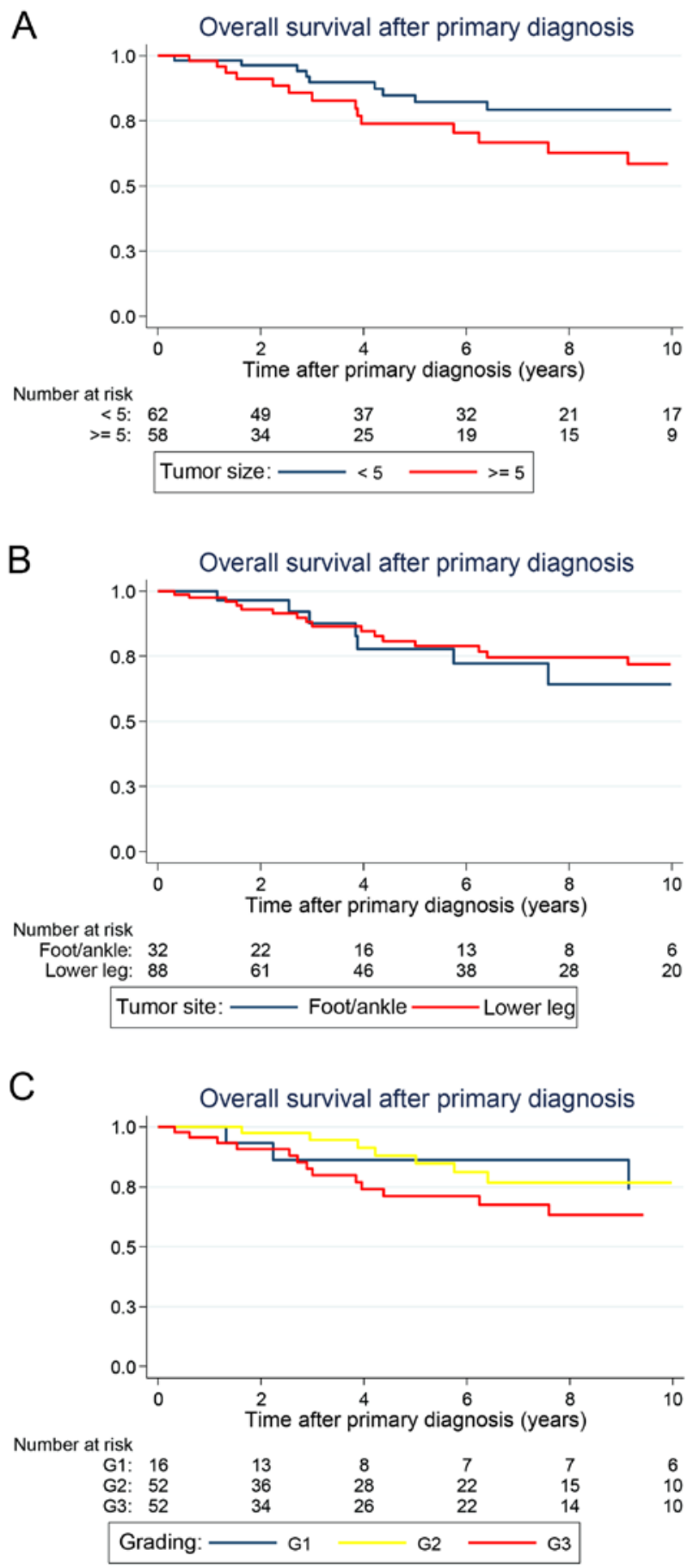

Figure 2. Effects of (A) tumor size, (B) tumor site and (C) histologic grading on overall survival.

significant indicator of diminished survival in the univariate analysis, but this finding was not significant in the multivariate analysis $(\mathrm{P}=0.071)$. Tumor size and negative surgical margin width also failed to reach prognostic significance in the multivariate analysis.

Postoperative function assessment. ESS, FFI and SF-36 were recorded a median of 7.4 years (range, 1.3-14.9) after the last surgical intervention. TESS and SF-36 could be obtained from a total of 30 patients while FFI was obtained from 27 patients with STS of the foot and ankle. Adjuvant radiation 
A

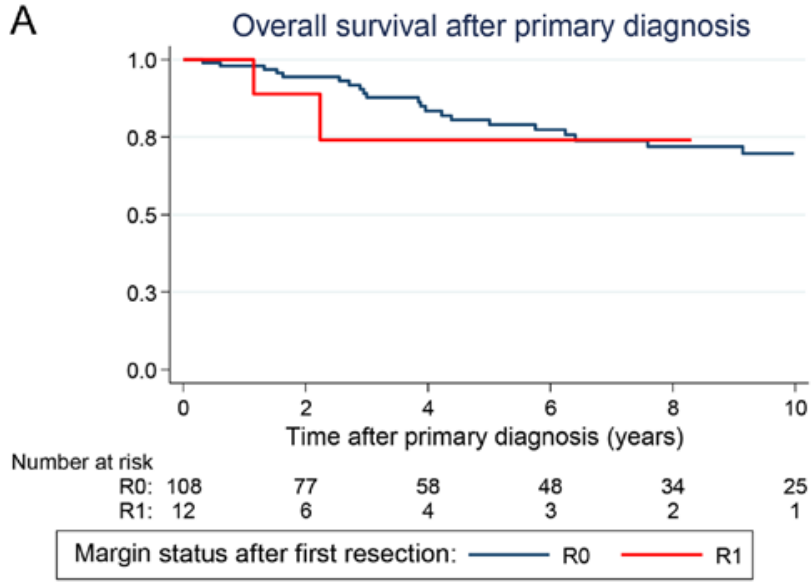

B

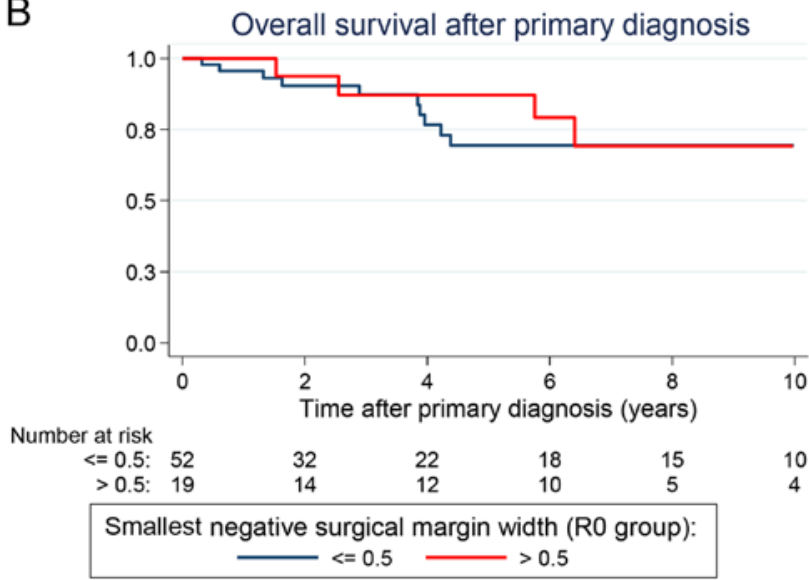

C

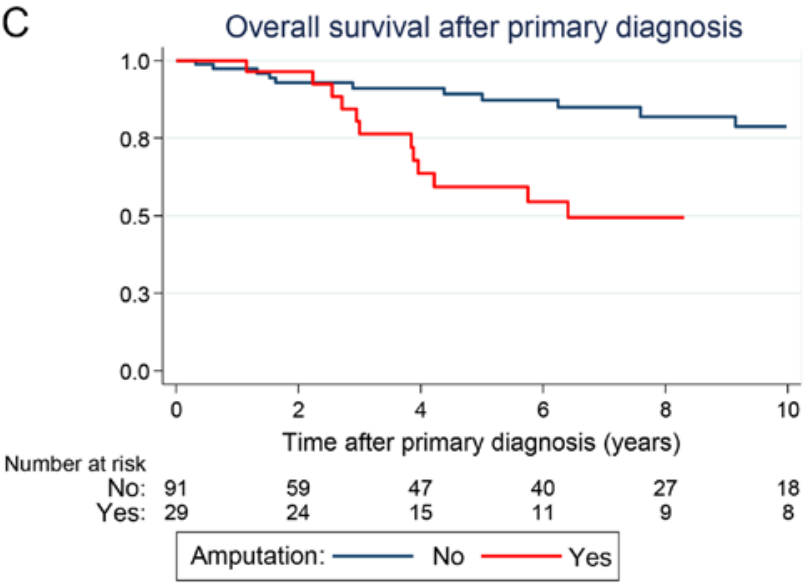

Figure 3. Effects of (A and B) surgical margins and (C) amputation on overall survival.

led to slightly decreased TESS scores indicating greater disabilities when compared with untreated patients, although the difference was not statistically significant (Table IV). Furthermore, radiation increased the FFI scores in a significant manner which inversely indicates a decreased foot function in these patients. Primary wound closure and plastic surgical soft tissue coverage led to similar functional outcomes. Lower histologic grades were associated with slightly better functional outcomes resulting in higher TESS and lower FFI scores when compared with higher histologic grades. However, this distribution failed to reach statistical significance in our analysis.

\section{Discussion}

In the present study, surgical margins attained at the resection of the primary tumor did not influence LRFS and OS. Resections with negative (R0) and microscopic positive margins (R1) led to a similar outcome in our patient population. This finding is in agreement with several studies assessing the impact of surgical margins on local control and survival. Kim et al analyzed numerous clinical and pathologic variables in 111 patients with extremity STS and could not determine any prognostic significance of positive margins on local recurrence and OS (25). Published in 2015 by Willeumier et al, positive margins significantly decreased LRFS, but did not influence the OS in 127 patients with extremity STS (26). A similar observation was made by McKnee et al assessing the predictive role of surgical margins in 111 extremity STS patients (27). To date, the largest study that analyzed the outcome of distal extremity STS was reported by Lin et al from the MD Anderson Cancer Center (19). In 115 patients with hand and foot STS, positive margins were associated with an increased risk for local recurrence, but did not diminish OS. In accordance to our findings, STS histology, grading, size and localization were not found to be significant prognostic factors of OS and amputations did not result in an improved outcome. Similar observations were made by Kozawa et al when analyzing 24 patients with foot STS (23).

Nevertheless, these findings are contradictory to several large studies as well. In 2010, Novais et al demonstrated that positive margins increase the risk of local recurrence and diminish the OS in 248 patients with extremity STS (12). Potter et al confirmed the adverse prognostic significance of positive margins on LRFS and OS in 363 patients with extremity STS (28). In the Memorial Sloan-Kettering Cancer Center (MSLKCC), Pisters et al assessed various prognostic factors in 1,041 patients with extremity STS during a median follow-up of 3.95 years and reported diminished LRFS and OS rates in patients left with microscopic positive margins (10). However, another large study by Gronchi et al from the Istituto Nazionale Tumori in Milan analyzed the outcome of 911 patients with extremity STS presenting a long-term median follow-up of 8.92 years (4). Notably, microscopic margin status failed to reach statistical significance as an independent predictive factor in this long-term survival analysis. Finally, Kandel et al presented a meta-analysis including 32 retrospective and prospective studies in 2013 (29). Here, most studies failed to establish a strong correlation between surgical margins and OS.

However, although the prognostic significance of positive margins still remains unclear in extremity STS, the same conclusions might be drawn. All recently published studies suggested a less radical surgical approach with limb- and function-sparing resections when feasible without leaving microscopic positive margins. As indicated by Lin et al, Kozawa et al and our current study, amputations did not result in an improved OS in patients with distal 
Table IV . Correlation between functional indices and different tumor/treatment characteristics.

\begin{tabular}{|c|c|c|c|c|c|c|c|c|c|}
\hline & \multicolumn{3}{|c|}{ TESS } & \multicolumn{3}{|c|}{ FFI } & \multicolumn{3}{|c|}{ SF-36 } \\
\hline & $\mathrm{N}$ & Mean \pm SD & P-value & $\mathrm{N}$ & Mean \pm SD & P-value & $\mathrm{N}$ & Mean \pm SD & P-value \\
\hline \multicolumn{10}{|c|}{ Radiation } \\
\hline No & 12 & $70.3 \pm 9.6$ & & 10 & $20.2 \pm 13.8$ & & 11 & $60.0 \pm 30.8$ & \\
\hline Yes & 18 & $59.5 \pm 19.6$ & & 17 & $38.9 \pm 26.0$ & & 17 & $57.6 \pm 33.2$ & \\
\hline Total & 30 & $63.8 \pm 17.0$ & $0.112^{\mathrm{a}}$ & 27 & $32.0 \pm 23.8$ & $0.042^{\mathrm{a}}$ & 28 & $58.6 \pm 31.7$ & $0.705^{\mathrm{a}}$ \\
\hline \multicolumn{10}{|c|}{ Primary wound closure } \\
\hline No & 10 & $60.3 \pm 18.0$ & & 10 & $35.1 \pm 22.7$ & & 9 & $55.0 \pm 35.3$ & \\
\hline Yes & 20 & $66.0 \pm 17.0$ & & 17 & $31.2 \pm 25.4$ & & 19 & $60.3 \pm 31.7$ & \\
\hline Total & 30 & $63.8 \pm 17.0$ & $0.335^{\mathrm{a}}$ & 27 & $32.0 \pm 23.8$ & $0.692^{\mathrm{a}}$ & 29 & $58.6 \pm 31.7$ & $0.776^{\mathrm{a}}$ \\
\hline \multicolumn{10}{|c|}{ Grading } \\
\hline G1 & 6 & $74.7 \pm 4.7$ & & 4 & $21.7 \pm 16.1$ & & 5 & $59.0 \pm 29.0$ & \\
\hline $\mathrm{G} 2$ & 13 & $62.9 \pm 18.7$ & & 13 & $34.0 \pm 27.0$ & & 12 & $62.1 \pm 36.3$ & \\
\hline G3 & 11 & $59.1 \pm 17.5$ & & 10 & $33.4 \pm 22.9$ & & 11 & $54.5 \pm 30.0$ & \\
\hline Total & 30 & $63.8 \pm 17.0$ & $0.107^{\mathrm{b}}$ & 27 & $32.0 \pm 23.8$ & $0.732^{\mathrm{b}}$ & 28 & $58.6 \pm 31.7$ & 0.773 \\
\hline
\end{tabular}

${ }^{\mathrm{a}}$ Mann-Whitney U test; ${ }^{b}$ Kruskal-Wallis test. TESS, Toronto Extremity Salvage Score; FFI, Foot Function Index; SF-36, 36-Item Short Form Health Survey; SD, standard deviation.

extremity STS $(19,23)$. Moreover, none of the three studies could identify any prognostic significance of positive margins on OS in distal extremity STS. Finally, OS was not improved significantly by wide and radical excisions in our series. Close and wide negative margins had a similar outcome within the R0 resected subgroup. Although a trend in favor of negative margins $>1 \mathrm{~mm}$ was observed, no statistical significance could be established. Notably, amputation during the course of disease was associated with a significant diminished outcome in the univariate analysis. However, it failed to reach statistical significance in the multivariate analysis and it has to be stated that patients that had to undergo amputation suffered from more aggressive and local extensive tumors. Hence, the unfavorable outcome of amputation was rather a result of the aggressive tumor biology than the procedure itself. Taken together, these findings support a surgical approach with more conservative resections that preserve function and structure at the distal lower extremities.

In our survival analysis, only age and gender emerged as independent predictors of OS. Tumor characteristics including histology, size and depth did not affect OS. Noteworthy, histologic grade also failed to reach prognostic significance in our analysis. Regarding adjuvant treatment modalities, radiation did not improve LRFS and OS in our patient population, but resulted in impaired foot function. In accordance, Lin et al were not able to detect any beneficial effects of radiation on LRFS and OS in their hand and foot sarcoma patients (19). However, these findings have to be interpreted with caution because of the relatively small number of patients included in both studies assessing distal extremity STS. In 2014, a randomized, prospective study conducted by the National Cancer Institute in Bethesda included 141 patients with extremity STS and revealed that patients who underwent limb-sparing surgery with adjuvant radiation had a lower risk of local failure when compared with patients who underwent surgery without radiation (30). It therefore seems reasonable to include adjuvant radiation when the potential for local recurrence is elevated due to high tumor grade or aggressive tumor progression.

Finally, the reservation must be made that our series included only patients with STS that were suitable for further surgical treatment. Patients with extensive tumors which could not be approached surgically because of rapid disease progression and therefore with less favourable outcome were not assessed in this study. Hence, our findings are only applicable to the selected group of patients where further surgical treatment was possible and not to all patients with STS of the distal lower extremities. This implies a study selection bias which has to be acknowledged.

In conclusion, this study provides long-term follow-up data that may help clinicians estimate the prognosis of patients with STS of the distal lower extremities. Adverse prognostic features include male gender and age $>60$ years at the time point of primary diagnosis. The data from this study could not underscore the long-term benefit of negative margins achieved at the resection of the primary tumor or the recurring tumor. Although reconstructive plastic surgery can frequently reduce functional impairment at the distal lower extremities, the surgical approach to attaining negative margins can be associated with considerable morbidity and should, therefore, be weighed up carefully. Surgical efforts should aim at function-sparing resections when feasible with negative margins. Here, close negative margins seem to be adequate. When the goal of achieving negative margins will require major functional impairment of the extremity, a decision should be made in each case based on the biology of the STS, the health status of the patient and the decision of the informed patient. 


\section{References}

1. Jemal A, Siegel R, Ward E, Murray T, Xu J and Thun MJ: Cancer statistics, 2007. CA Cancer J Clin 57: 43-66, 2007.

2. Fernebro J, Bladström A, Rydholm A, Gustafson P, Olsson H, Engellau $\mathrm{J}$ and Nilbert $\mathrm{M}$ : Increased risk of malignancies in a population-based study of 818 soft-tissue sarcoma patients. Br J Cancer 95: 986-990, 2006.

3. Billingsley KG, Lewis JJ, Leung DH, Casper ES, Woodruff JM and Brennan MF: Multifactorial analysis of the survival of patients with distant metastasis arising from primary extremity sarcoma. Cancer 85: 389-395, 1999.

4. Gronchi A, Casali PG, Mariani L, Miceli R, Fiore M, Lo Vullo S, Bertulli R, Collini P, Lozza L, Olmi P, et al: Status of surgical margins and prognosis in adult soft tissue sarcomas of the extremities: A series of patients treated at a single institution. J Clin Oncol 23: 96-104, 2005.

5. Kaushal A and Citrin D: The role of radiation therapy in the management of sarcomas. Surg Clin North Am 88: 629-646, 2008.

6. Singer S, Demetri GD, Baldini EH and Fletcher CD: Management of soft-tissue sarcomas: An overview and update. Lancet Oncol 1: $75-85,2000$

7. Collin C, Godbold J, Hajdu S and Brennan M: Localized extremity soft tissue sarcoma: An analysis of factors affecting survival. J Clin Oncol 5: 601-612, 1987.

8. Pisters PW and Pollock RE: Staging and prognostic factors in soft tissue sarcoma. Semin Radiat Oncol 9: 307-314, 1999.

9. Gaynor JJ, Tan CC, Casper ES, Collin CF, Friedrich C, Shiu M, Hajdu SI and Brennan MF: Refinement of clinicopathologic staging for localized soft tissue sarcoma of the extremity: A study of 423 adults. J Clin Oncol 10: 1317-1329, 1992.

10. Pisters PW, Leung DH, Woodruff J, Shi W and Brennan MF: Analysis of prognostic factors in 1,041 patients with localized soft tissue sarcomas of the extremities. J Clin Oncol 14 1679-1689, 1996.

11. Matsumoto S, Ahmed AR, Kawaguchi N, Manabe J and Matsushita Y: Results of surgery for malignant fibrous histiocytomas of soft tissue. Int J Clin Oncol 8: 104-109, 2003.

12. Novais EN, Demiralp B, Alderete J, Larson MC, Rose PS and Sim FH: Do surgical margin and local recurrence influence survival in soft tissue sarcomas? Clin Orthop Relat Res 468: 3003-3011, 2010

13. Stojadinovic A, Leung DH, Hoos A, Jaques DP, Lewis JJ and Brennan MF: Analysis of the prognostic significance of microscopic margins in 2,084 localized primary adult soft tissue sarcomas. Ann Surg 235: 424-434, 2002.

14. Trovik CS, Bauer HC, Alvegård TA, Anderson H, Blomqvist C, Berlin O, Gustafson P, Saeter G and Wallöe A: Surgical margins, local recurrence and metastasis in soft tissue sarcomas: 559 surgically-treated patients from the Scandinavian Sarcoma Group Register. Eur J Cancer 36: 710-716, 2000.

15. Eilber FC, Rosen G, Nelson SD, Selch M, Dorey F, Eckardt J and Eilber FR: High-grade extremity soft tissue sarcomas: Factors predictive of local recurrence and its effect on morbidity and mortality. Ann Surg 237: 218-226, 2003.
16. Karakousis CP and Driscoll DL: Treatment and local control of primary extremity soft tissue sarcomas. J Surg Oncol 71: 155-161, 1999.

17. Sadoski C, Suit HD, Rosenberg A, Mankin H and Efird J: Preoperative radiation, surgical margins, and local control of extremity sarcomas of soft tissues. J Surg Oncol 52: 223-230, 1993.

18. Stojadinovic A, Leung DH, Allen P, Lewis JJ, Jaques DP and Brennan MF: Primary adult soft tissue sarcoma: Time-dependent influence of prognostic variables. J Clin Oncol 20: 4344-4352, 2002.

19. Lin PP, Guzel VB, Pisters PW, Zagars GK, Weber KL, Feig BW, Pollock RE and Yasko AW: Surgical management of soft tissue sarcomas of the hand and foot. Cancer 95: 852-861, 2002.

20. Karakousis CP, De Young C and Driscoll DL: Soft tissue sarcomas of the hand and foot: Management and survival. Ann Surg Oncol 5: 238-240, 1998.

21. Scully SP, Temple HT and Harrelson JM: Synovial sarcoma of the foot and ankle. Clin Orthop Relat Res 364: 220-226, 1999.

22. Selch MT, Kopald KH, Ferreiro GA, Mirra JM, Parker RG and Eilber FR: Limb salvage therapy for soft tissue sarcomas of the foot. Int J Radiat Oncol Biol Phys 19: 41-48, 1990.

23. Kozawa E, Nishida Y, Nakashima H, Tsukushi S, Toriyama K, Kamei $\mathrm{Y}$ and Ishiguro N: Foot sarcomas: Factors affecting oncological and functional outcomes. Oncol Lett 3: 82-88, 2012.

24. Schemper M and Smith TL: A note on quantifying follow-up in studies of failure time. Control Clin Trials 17: 343-346, 1996.

25. Kim YB, Shin KH, Seong J, Roh JK, Kim GE, Hahn SB and Suh CO: Clinical significance of margin status in postoperative radiotherapy for extremity and truncal soft-tissue sarcoma. Int $\mathrm{J}$ Radiat Oncol Biol Phys 70: 139-144, 2008.

26. Willeumier J, Fiocco M, Nout R, Dijkstra S, Aston W, Pollock R, Hartgrink H, Bovée J and van de Sande M: High-grade soft tissue sarcomas of the extremities: Surgical margins influence only local recurrence not overall survival. Int Orthop 39: 935-941, 2015.

27. McKee MD, Liu DF, Brooks JJ, Gibbs JF, Driscoll DL and Kraybill WG: The prognostic significance of margin width for extremity and trunk sarcoma. J Surg Oncol 85: 68-76, 2004

28. Potter BK, Hwang PF, Forsberg JA, Hampton CB, Graybill JC, Peoples GE and Stojadinovic A: Impact of margin status and local recurrence on soft-tissue sarcoma outcomes. J Bone Joint Surg Am 95: e151, 2013.

29. Kandel R, Coakley N, Werier J, Engel J, Ghert M and Verma S; Sarcoma Disease Site Group of Cancer Care Ontario's Program in Evidence-Based Care: Surgical margins and handling of soft-tissue sarcoma in extremities: A clinical practice guideline. Curr Oncol 20: e247-e254, 2013.

30. Beane JD, Yang JC, White D, Steinberg SM, Rosenberg SA and Rudloff U: Efficacy of adjuvant radiation therapy in the treatment of soft tissue sarcoma of the extremity: 20-year follow-up of a randomized prospective trial. Ann Surg Oncol 21: 2484-2489, 2014. 